\title{
Are natural resources a curse?
}

\author{
Many economies in the developing world rely heavily on the export of minerals. Richard Jones \\ discusses what the development of new nanomaterials will mean for such countries.
}

\begin{abstract}
One of the most potent promises of nanotechnology is that it will lead to new materials that are stronger, cheaper and more functional than existing ones. This kind of technology shift will produce losers as well as winners, and a number of activists have suggested that developing countries that depend heavily on the production of a narrow range of commodities - such as copper, rubber or cotton - might lose out if the promise of new nanomaterials comes to fruition. For example, if carbon nanotubes replace the copper wires currently used for the transmission of electricity, what would happen to a country like Zambia, which depends on minerals, largely copper, for $26 \%$ of its foreign exchange ${ }^{1}$ ?
\end{abstract}

Of course, the prices of commodities like copper are notoriously volatile, but only some of this volatility is due to technological changes. In the longer term, however, major technological developments - such as the replacement of copper wire with fibre-optic cable for the transmission of data - influence the demand for copper and other natural resources. But it is important to be realistic about just how imminent such material shifts are likely to be. Take the possible replacement of copper wires by carbon nanotubes as an example: first, carbon nanotubes are orders of magnitude more expensive than copper; second, nanotubes can either be conducting or semiconducting, and at present there is no reliable method of making samples that contain just conducting (or indeed just semiconducting) nanotubes.

\section{Can nanotechnology help countries that depend on commodities to add value to their exports?}

Moreover, for any application, the reasons for the choice of one particular material are multi-dimensional, which leads to an intrinsic conservatism in the choice of materials. After all, synthetic

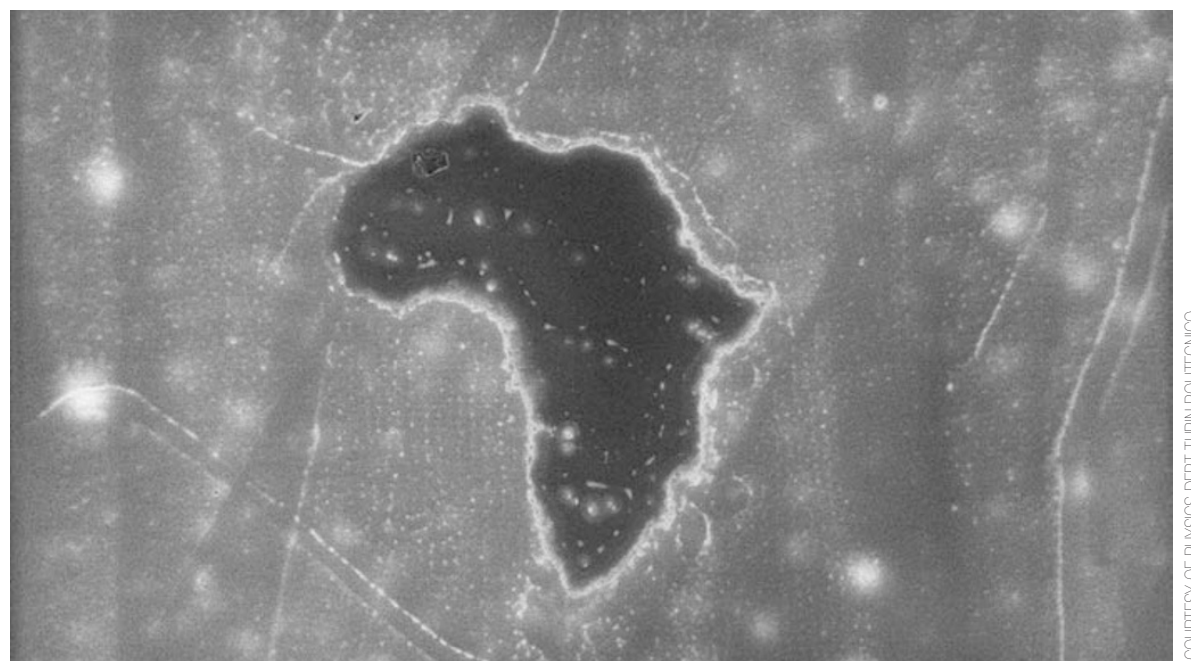

Coming to terms with the impact of nanotechnology will be important for many developing countries, especially those in Africa, shown here in an atomic force microscope image that measures $700 \mathrm{~nm}$ across.

versions of rubber have been available for more than 70 years, yet natural rubber is still in demand as a material with good performance at the right price. Electricity transmission provides another example: although the cables that carry electrical power over large distances in national grids are made from aluminium rather than copper because of its low cost and light weight, copper still dominates for wiring buildings because of the ease with which wires can be joined.

Perhaps at the root of these worries about commodity replacement is the idea that nanotechnology is a kind of alchemy in which the precise placement of atoms will allow new materials with any property to be designed at will. This is an important element in the rhetoric that has grown up around nanotechnology, and there are certainly some interesting case studies that can be cited in its support. The difference between carbon black and carbon nanotubes shows very clearly how dramatic new properties can arise as a result of precision in atomic arrangements, and bandgap engineering in semiconductors and optical metamaterials shows how the ability to control structure at the nanoscale can lead to materials with new electronic and optical properties.

This is a fascinating theme for the future, but there are also forces acting in the opposite direction. As new nanoscale physics leads to the design of new devices, there is also an increasing demand for rare and obscure elements that have some precise set of electrical, optical and magnetic properties. In a very short time, rare elements can be transformed from laboratory curiosities to become the foundation of major industries. One example of this is indium, which is used to make the thin films of the transparent conductor indium tin oxide that are essential components in liquid-crystal displays. Indeed, the boom in flat-screen TVs and liquid-crystal displays has led to a tenfold increase in the price of indium over a three-year period. Other quiet corners of the periodic table that have also entered the spotlight in recent 
years include tantalum, which is used in the high-performance capacitors found in mobile phones and other consumer electronics, and hafnium, whose compounds will be used as gate dielectrics in next-generation microprocessors from Intel and IBM.

These shifts in demand, and the price gyrations they have led to (exacerbated by the relatively small total amounts of material being traded), certainly have had an impact on the developing world. Most of the world's tantalum is minded in Australia and Canada, but significant amounts of a tantalum-bearing ore called Coltan are found in the Eastern Congo, and these reserves have been blamed for making the difficult situation in the country worse by financing rebel armed groups and promoting warfare for control of these resources. This leads to a larger question - is it an unalloyed blessing to have an economy dependent on commodities? Some development economists talk about a 'resources curse', and empirical evidence suggests that developing economies that are heavily dependent on exports of minerals have slower rates of growth and higher levels of income inequality than comparable countries with fewer natural resources.

Even if some of the proposed scenarios for the wholesale replacement of commodities like copper by new nanomaterials are far-fetched, it is clear that commodity markets are capricious and the position of countries that depend on a small number of minerals or other basic products is not ideal. Although nanotechnology is unlikely to be the biggest driver of the vertiginous price swings that commodities like copper have been subject to in recent years, it is certainly not a stabilizing factor. However, one can ask a positive question - can nanotechnology help countries that depend on commodities to add value to their exports in a way which mitigates the resources curse?

The conventional wisdom is that such countries should make efforts to 'move up the value chain' by creating the technology needed to innovate and develop the kind of higher-technology-manufactured exports that are associated with faster rates of development, real wage growth and reduction in poverty. This is, however, easier said than done because it requires significant structural changes in these countries. In particular, there is a need for developing countries to improve the skills and technological capacity of their workforce. This is an enormous challenge, but if it can be addressed, the benefits would spread well beyond the world of nanotechnology.

Published online: 21 0ctober 2007.

Reference

1. www.merid.org/nano/commoditiesworkshop/ backgroundmaterials.php

Richard Jones is in the Department of Physics and Astronomy at the University of Sheffield.e-mail:r.a.l.jones@sheffield.ac.uk

In Thesis next month:

Michael Helmus and Anil Rao on the commercialization of academic research.

This article is part of the Global Theme on Poverty and Human Development, organized by the Council of Science Editors. All articles from the Nature Publishing Group are available free at www.nature.com/povhumdev. The content from all participating journals can be found at http://www.councilscienceeditors.org/ globalthemeissue.cfm 